\title{
Disruptive behaviors among nurses in Israel - association with listening, wellbeing and feeling as a victim: a cross-sectional study
}

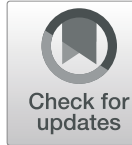

Sigal Shafran Tikva ${ }^{1,2,3^{*}}$, Avraham N. Kluger ${ }^{3}$ and Yulia Lerman ${ }^{1}$

\begin{abstract}
Objectives: To examine the association between listening and disruptive behaviors and the association between disruptive behavior and the wellbeing of the nurse. To test whether constructive and destructive listening has an incremental validity.
\end{abstract}

Methods: A structured questionnaire survey that measured the (constructive \& destructive) listening climate at work, exposure to disruptive behaviors, well-being and feeling as a victim. We presented this survey using the Qualtrics software.

Results: Of the final sample of 567 respondents who reported that they were nurses, $M_{\text {Age }}=38.41,67 \%$ indicated that they were exposed to some form of disruptive behavior. Experiencing listening in the ward was associated with low levels of exposure to disruptive behaviors; exposure to disruptive behaviors, in turn, predicted reduction in the nurses' wellbeing; the reduction in wellbeing was especially pronounced among nurses who felt like a victim. Each of the facets of the listening measure - constructive listening and destructive listening — had incremental validity in predicting exposure to disruptive behaviors. Finally, the effect of exposure to disruptive behavior on wellbeing was curvilinear.

Conclusions: Disruptive behavior is a major challenge to the workplace well-being for nurses. The victim mentality has an adverse impact on nurses. Preventive efforts aimed at reducing disruptive behaviors among nurses and decreasing their sense of victimization are crucial for the well-being of nurses.

Keywords: Disruptive behavior, Feeling as a victim, Listening, Nurses, Wellbeing

\section{Introduction}

Disruptive behavior which is expressed in many different forms is an undesirable conduct among colleagues in the workplace. Disruptive behavior is sometimes referred to as lateral violence, bullying, workplace incivility, lateral hostility, horizontal hostility, horizontal violence, interpersonal conflict and disruptive behavior [5, 13, 31, 48]. The construct of disruptive behavior, using one name or another, among nurses has been discussed for over a century [8]. We chose the term "disruptive behavior" which refers to the negative behaviors among peer nurses following the term used by The Joint Commission [18] .

\footnotetext{
* Correspondence: tsigal@hadassah.org.il

${ }^{1}$ Hadassah University medical Hospital, Jerusalem, Israel

${ }^{2}$ Jerusalem College of Technology, Jerusalem, Israel

Full list of author information is available at the end of the article
}

Disruptive behavior is commonly experienced by nurses around the world across cultures and borders [1, 2, 44], it also affects nursing students and new novice nurses $[3,9]$.

In Israel, a study aimed to describe the prevalence of ICU nurse bullying and what measures were taken to prevent it, showed that the levels of bullying were low to moderate $(29 \%)$ and the level of prevention was weak or moderate. The higher the level of bullying, the lower the level of prevention [15].

Disruptive behavior has serious implications for the nurse, the organization and even the patient. With regard to the nurse, the literature reports physical and mental consequences that may result in weight loss, depression, sleep problems, anxiety, post-trauma-syndrome disorder (PTSD), and suicidal tendencies [5, 34, 37, 42]. For example, in a cohort study, bullying was found to be

(C) The Author(s). 2019 Open Access This article is distributed under the terms of the Creative Commons Attribution 4.0 International License (http://creativecommons.org/licenses/by/4.0/), which permits unrestricted use, distribution, and reproduction in any medium, provided you give appropriate credit to the original author(s) and the source, provide a link to the Creative Commons license, and indicate if changes were made. The Creative Commons Public Domain Dedication waiver (http://creativecommons.org/publicdomain/zero/1.0/) applies to the data made available in this article, unless otherwise stated. 
a predicting factor for mental health problems, such as anxiety, depression, and fatigue [36]. Exposure to disruptive behavior is also related to a decline in work satisfaction [35], increased burnout [1], and damaged relationships among colleagues [13].

However, disruptive behavior does not only harm the victimized nurse, it also has a negative impact both on the organization and the patients. In fact, disruptive behavior has a ripple effect because it leads to an increase in absenteeism, high turnover of nurses and tendency to leave the profession. A shortage of nurses could lead to damage in quality of care and decline in patients' satisfaction $[5,13]$. Indeed, bullying has a negative influence on nurse-assessed patient quality through their effect on perceptions of patient safety risk [42]. Moreover, nurses who are victims of disruptive behaviors tend to pay less attention to tasks, which increases the risk of making clinical errors [5], and adverse events [34]. Thus, it is not surprising that some reviews suggested that disruptive behavior ".. . can have a significant impact on care delivery, which can adversely affect patient safety and quality outcomes of care" [39], and that the Joint Commission (2008) stated, "Intimidating and disruptive behaviors can foster medical errors, contribute to poor patient satisfaction and to preventable adverse outcomes, increase the cost of care, and cause qualified clinicians, administrators and managers to seek new positions in more professional environments" [18].

Given the potential dire consequences of disruptive behavior, it is desirable to understand its antecedents. According to one review, the antecedents of workplace bullying fall into four main categories: role characteristics, quality of the relationship, leadership style and organizational culture [46]. Findings in another study showed three organizational factors that contribute to bullying and, the relationship between bullying and the resultant consequences: informal organizational alliances, organizational tolerance and reward of bullying and misuse of legitimate organizational processes and procedures [19].

In a study aimed to examine work climate, bullying and job performance, results showed that work bullying had a mediational role between most of the work climate dimensions and nurse outcomes [33]. Here, we focus on the role of quality of relationship. One key antecedent to relationship is listening quality. Indeed, current definitions of the construct of listening emphasize that relationship is one out of three components of the listening construct: attention, comprehension, and (positive) intention [20, 21]. Specifically, speakers develop a perception that they are being listened to when they perceive that the other person pays attention to them, understands them, and relates to them in a positive manner (non-judgmental, empathic, etc.). Moreover, empirical studies suggest that listening improves liking and relationships in all spheres of life, such as among strangers [29], and in marriage [6]. Moreover, employees who perceive that their supervisors listen, enjoy higher levels of job satisfaction $[14,45]$ and higher levels of psychological safety [7]. Similarly, listening was highly correlated with trust in dyads such as patient/physician [40], customer/salesperson [12], and suspect/detective [4]. We propose that listening among peers, such as among nurses, is also very likely to send signals of positive relationships, and thus be associated with a reduction in experiencing disruptive behaviors. To the best of our knowledge, the relationship between listening and the degree of exposure to disruptive behavior has not yet been investigated.

However, listening is correlated with lower levels of violence in domains other than nursing. Specifically, families, couples, marital, elderly people and children [11, 17, 23, 30, 32].

\section{Listening}

Listening is a multi-dimensional construct that includes attention to the speaker, comprehension of the speaker, and a relational aspect, such as being empathic and nonjudgmental [38]. Yet, measurement of perceived listening indicates that people tend to perceive "constructive" and "destructive" aspects of listening [25]. Therefore, in the current study, we sampled items tapping both the constructive and destructive aspects of listening.

\section{Interventions}

In a systematic review aimed to identify best practices for preventing and managing disruptive behaviors among staff nurses, the best method that was found to control and stop the phenomenon involves cognitive rehearsal of responses to common behaviors [27, 43]. Stagg et al., and Laschinger et al., found that authentic leadership had a negative direct effect on workplace bullying, which in turn had a direct positive effect on emotional exhaustion [27]. In a study aimed to evaluate role-play of bullying in nursing practice simulation as an active learning strategy, the results showed that role-play is a highly effective pedagogy, eliciting learning at both the cognitive and affective domains [47].

Several empirical studies of listening perceptions indicated that items reflecting good listening load on a separate factor than items reflecting poor listening. This led Kluger and Bouskila-Yam to propose the constructs of constructive listening and destructive listening [25] An example of an item showing high loading on constructive listening is " $\mathrm{X}$ tries hard to understand what I am saying", and for destructive listening is " $\mathrm{X}$ discounts or explains away my feelings." Indeed, Kluger and Zaidel [26] have shown not only that listening items form constructive and destructive listening factors, but they have differential validity [26]. Moreover, in a study 
of layperson theories of good listening that generated more than 70 listening items, items that were indicators of poor listening, did not load on the factor of good listening [28].

\section{Wellbeing}

Well-being is good or satisfactory condition of existence; a state characterized by health, happiness, and prosperity. The symptoms of poor wellbeing are insomnia, poor mood, depression, decrease in motivation, self- evaluation etc.

Wellbeing is the balance point between an individual's resource pool and the challenges faced [10].

In summary, in this study we tested the following model regarding disruptive behaviors:

\section{The objectives of the study}

(a) To examine the association between listening and disruptive behaviors.

(b) To examine whether constructive and destructive listening has an incremental validity.

(c) To test the association between disruptive behavior and the wellbeing of the nurse.

(d) To test the role of feeling as a victim in augmenting the effects of disruptive behaviors on wellbeing.

\section{Methods}

\section{Data source and participants}

We developed a structured questionnaire survey to measure the (constructive \& destructive) listening climate at work, exposure to disruptive behaviors, wellbeing and feeling as a victim. We conducted this survey using the Qualtrics software. First, we attempted to obtain permission to distribute the questionnaire from several managers in health care organizations, but we were refused. Thus, we distributed it via social network (Facebook), e-mails and the snowball method. We invited staff nurses to fill in the questionnaire: "Staff nurses, please access the questionnaire that deals with our behaviors, between each other, in daily work,. Filling out the questionnaire on Facebook and e-mails allows anonymous expression. The questionnaire is friendly, short and can be filled with a smartphone. We would appreciate your time." In this way, we invited respondents to answer privately, without fear of supervisor involvement. This method also addressed concerns that respondents may have when answering questions regarding disruptive behavior. This distribution method allowed us to reach out to nurses from different organizations. Our invitation indicated that we were interested in examining behaviors between nurses; however, we did not mention "disruptive behaviors", to avoid bias. The data collection lasted 2 months and we posted three reminders.

Prior to the distribution of this survey, we obtained an approval from the Institutional Review Board of the Jerusalem College of Technology.

\section{Measurements}

Unless otherwise noted, we presented all items using a Likert scale ranging from $1=$ Does not reflect at all to $7=$ Reflects to a very large degree.

\section{Disruptive behaviors}

The main dependent variable was whether nurses had experienced disruptive behaviors from their nurses' colleagues within the last 6 months prior to the study. Specifically, we asked "In the past six months, if and to which extent were you exposed to behaviors (listed below) from the colleague's nurses in your workplace?" The disruptive-behavior list included experiencing negative remarks, verbal insults, humiliation in front of patients/staff member/ family, damaging authority, declining to assist with no reason, arrogant attitude, blaming, gossip and talking behind back, social isolation, and sexual harassment. A factor analysis indicated the presence of a single factor (only one factor had an eigenvalue $>1$ ). A scale constructed from these items was reliable, $\alpha=.93$.

\section{Listening}

We selected 12 items from the Facilitation Listening Survey [25] and adapted them to nurses. The items measured both constructive listening (seven items) and destructive listening (five items), however, we mixed the presentation of constructive and destructive items. Specifically, we asked "When nurses in my unit listen to each other or to me, most of the time they ..." Examples of constructive-listening items are "Listen attentively", "Allows another to fully express himself", "Trying to understand what has been said", and "Respects opinions even if they differ from theirs." Examples of destructivelistening items are "Not interested in listening to others", "Do not pay attention to what is said to them", and "Speak back aggressively." Both the constructive listening scale, $\alpha=.93$, and the destructive-listening scale, $\alpha=.88$, were reliable.

\section{Wellbeing (symptoms of poor wellbeing)}

We used 14 items to assess the wellbeing of the nurses by asking them for a rating of the degree to which they feel "Poor mood", "Anxiety", "Depression", "Concentration difficulties", "Insomnia", "Changes in eating habits", "Various types of pain", "Absenteeism", "Diminished quality of life off work", "Decrease in self-evaluation", "Decrease in motivation", "Decrease in satisfaction", "Turnover thoughts 
off the disruptive workplace", and "Other". Most respondents did not answer "Other", so we discarded this item. Although a factor analysis indicated that these 13 items form three factors, they were highly correlated, and thus we created a single scale, $\alpha=.92$. However, we also created sub-scales based on the factor analysis and labeled these scales Physiological Symptoms (e.g., "Insomnia"), $\alpha=.87$, Motivation (e.g., "Decrease in motivation"), $\alpha=.90$, and Negative Affect (e.g., "Depression”), $\alpha=.84$.

\section{Feeling as a victim}

Out of the 10 items we developed to assess attitudes towards disruptive behaviors, a factor analysis indicated that four of these form a factor tapping victimhood. Because we deemed victimhood as a key outcome, we retained only these items. The items were "If I get hurt, I will quit", "I ask for shifts without that person", "When I see someone hurt, I know my turn will arrive", and "I feel as a victim", $\alpha=.67$.

\section{Socio-demographic}

We also collected data regarding nurse's age, gender, marital status, religion, type of organization working in (general hospital, geriatric, rehabilitation, etc.), work unit (ICU, internal medicine, etc.), and organization ownership (public, private or combined).

\section{Statistical analysis}

We tested predictions about simple associations with Pearson correlations, and predictions regarding incremental validity and interaction with hierarchicalmultiple regression.

\section{Results}

A total of 637 respondents clicked the web link of the questionnaire. Yet, there were empty records or records with extensive missing data. We excluded these records and obtained a final sample of 567 respondents who reported that they were nurses (i.e., licensed, registered, or practical nurses), $\mathrm{M}_{\mathrm{Age}}=38.41, S D=10.5, \quad 90.3 \%$ female. Socio-demographic characteristics of this sample are presented in Table 1.

\section{Statistical analysis}

First, we probed the prevalence of all disruptive behavior and found that $67.2 \%$ of the respondents indicated that they were exposed to some form of disruptive behavior (those that were not exposed, marked 1 or other very low score on the rating scale of disruptive behaviors). Specifically, we present in Fig. 1 the mean of the exposure scales for each type of disruptive behavior in a descending order.

Second, we tested the correlations of the two listening scales with the disruptive-behavior scale and the
Table 1 Socio-demographic data of participants $(N=567)$

\begin{tabular}{|c|c|c|}
\hline Variable & $N$ & $\%$ \\
\hline \multicolumn{3}{|l|}{ Gender } \\
\hline Female & 511 & 90.3 \\
\hline Male & 55 & 9.7 \\
\hline \multicolumn{3}{|l|}{ Religiosity } \\
\hline Secular & 378 & 76.8 \\
\hline Religious & 63 & 12.8 \\
\hline Traditional & 46 & 9.3 \\
\hline Ultra-Orthodox & 5 & 1 \\
\hline \multicolumn{3}{|l|}{ Educational level } \\
\hline Licensed practical nurse (LPN) & 7 & 1.2 \\
\hline Registered nurse (RN) & 83 & 14.7 \\
\hline Academic RN w BA & 309 & 54.8 \\
\hline Academic RN w MA/Ph.D & 165 & 29.3 \\
\hline \multicolumn{3}{|l|}{ Job rate } \\
\hline Full time & 351 & 61.9 \\
\hline Part time & 216 & 38.1 \\
\hline \multicolumn{3}{|l|}{ Shifts } \\
\hline Mixed & 300 & 53 \\
\hline Morning & 197 & 34.8 \\
\hline Evening & 37 & 6.5 \\
\hline Night & 32 & 5.7 \\
\hline \multicolumn{3}{|l|}{ Seniority in the current unit } \\
\hline Up to a year & 79 & 14 \\
\hline Between 1 and 2 years & 65 & 11.5 \\
\hline Between 2 and 4 Years & 91 & 16.1 \\
\hline More than 4 years & 331 & 58.5 \\
\hline \multicolumn{3}{|l|}{ Organization } \\
\hline General hospital & 370 & 75.4 \\
\hline Community care & 75 & 15.3 \\
\hline Geriatric medical center & 22 & 4.5 \\
\hline Psychiatric hospital & 17 & 3.5 \\
\hline Rehabilitation & 7 & 1.4 \\
\hline \multicolumn{3}{|l|}{ Current unit } \\
\hline $\mathrm{ICU}$ & 68 & 14 \\
\hline Internal & 57 & 11.7 \\
\hline Surgery & 52 & 10.7 \\
\hline Delivery \& Obstetric \& delivery room & 49 & 10.1 \\
\hline Children & 43 & 8.8 \\
\hline Operation Room & 41 & 8.4 \\
\hline Emergency Room & 32 & 6.6 \\
\hline Psychiatry & 16 & 3.3 \\
\hline Ambulatory & 11 & 2.3 \\
\hline Oncology & 10 & 2.1 \\
\hline Other & 107 & 22 \\
\hline
\end{tabular}


Table 1 Socio-demographic data of participants $(N=567)$ (Continued)

\begin{tabular}{lll}
\hline Variable & N & $\%$ \\
\hline Ownership & & \\
Public & 365 & 74 \\
Private & 45 & 9.1 \\
Mixed & 83 & 16.8 \\
\hline
\end{tabular}

remaining variables in our study. As can be seen in Table 2, the constructive- (destructive-) listening scale is negatively (positively) correlated with reporting exposure to disruptive behaviors. Third, we inspected the correlations between the listening scales, wellbeing, and subscales of wellbeing. As can be seen in Table 2, all of these correlations are significant, moderate in magnitude, and in the predicted direction. In addition, feeling as a victim showed the same pattern of correlations with the listening scales. To test the path model we used structural equation modeling (e.g., [24]). The results of this model are presented in Fig. 2. The model had a good fit to the data, $\mathrm{X}^{2}(2)=4.40, p=.11, R M S E A=.05$ $[.00, .12], S R M R=.03$. All the paths were significant at the .001 level.

Notably, the strong correlation between destructive listening and disruptive behaviors, $r=-.66$, could be an artifact of shared content between these two scales. Specifically, the destructive-listening scale contains items such as "Speak back aggressively." Such items are very similar to those of the disruptive behavior scale such as "condensation and demoing approach." On the other hand, the constructive-listening scale does not contain any items resembling disruptive behaviors. Yet Fig. 2 shows that the constructive-listening scale has an incremental validity in predicting disruptive behavior, such that item overlap between constructs could explain some, but definitely not all of the association between listening and the experience of disruptive behavior.

Finally, we tested the interaction between experiencing disruptive behavior and feeling as a victim in predicting wellbeing. Typically, interactions were tested with the following model $Y=a+b_{1} X_{1}+b_{2} X_{2}+b_{3} X_{1} X_{2}$, where significance of $\mathrm{b} 3$ indicates the presence of an interaction. However, a stringiest test [16] needs to allow for the possibility of non-linear effects of either $\mathrm{X}_{1}, \mathrm{X}_{2}$, or both, as follows $Y=a+b_{1} X_{1}+b_{2} X_{2}+b_{3} X 1^{2}+b_{4} X 2^{2}+b_{5} X_{1} X_{2}$, where the significance of $\mathrm{b} 5$ indicates the presence of an interaction, controlling both for the main effects of the predictors and for their curvilinear effects. The results of this test are presented in Table 3 and Fig. 3.

Given that age was negatively correlated with wellbeing and symptoms (see Table 2), we tested whether controlling for age would alter any of our conclusions. It did not. Specifically, adding age as a predictor of wellbeing in our path model (Fig. 2), changed the standardized path from disruptive behavior to wellbeing from .51 (Fig. 2) to .49. Similarly, controlling for age in the polynomial regression in Table 3 changed the standardized coefficient of the interaction term from .132 (Table 3) to $.124, \mathrm{t}=3.40, p=.0007$. Thus, age cannot serve as an alternative explanatory variable to our results.

\section{Discussion}

The results of a cross-sectional study of 567 Israeli nurses largely support our model. Experiencing listening in the ward was associated with experiencing low levels of exposure to disruptive behaviors; exposure to disruptive behaviors, in turn, predicted a reduction in the

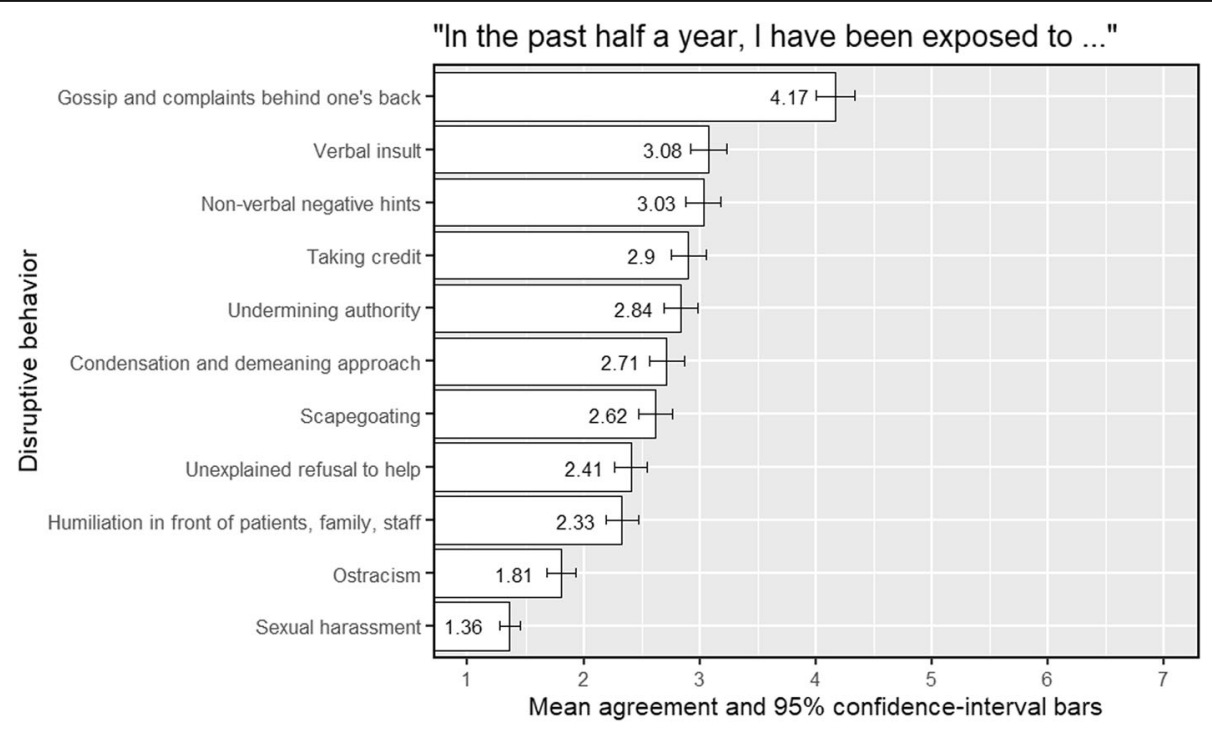

Fig. 1 Mean of the exposure for each type of disruptive behavior 
Table 2 Means, standard deviations, and correlations

\begin{tabular}{|c|c|c|c|c|c|c|c|c|c|c|c|}
\hline Variable & $M$ & SD & 1 & 2 & 3 & 4 & 5 & 6 & 7 & 8 & 9 \\
\hline \multicolumn{12}{|l|}{ Listening } \\
\hline 1. Constructive & 5.03 & 1.19 & & & & & & & & & \\
\hline 2. Destructive & 2.70 & 1.3 & $-.66^{* *}$ & & & & & & & & \\
\hline 3. Disruptive behavior & 2.65 & 1.35 & $-.58^{* *}$ & $.65^{* *}$ & & & & & & & \\
\hline Wellbeing & 2.89 & 1.39 & $-.35^{* *}$ & $.39^{* *}$ & $.51^{* *}$ & & & & & & \\
\hline 5. Physical & 2.80 & 1.38 & $-.25^{* *}$ & $.30^{* *}$ & $.40^{* *}$ & $.93^{* *}$ & & & & & \\
\hline 6. Motivation & 3.04 & 1.78 & $-.38^{* *}$ & $.41^{* *}$ & $.51^{* *}$ & $.89^{* *}$ & $.70^{* *}$ & & & & \\
\hline 7. Negative Affect & 2.05 & 1.02 & $-.28^{* *}$ & $.32^{* *}$ & $.43^{* *}$ & $.85^{* *}$ & $.72^{* *}$ & $.71^{* *}$ & & & \\
\hline 8. Victim & 2.58 & 1.33 & $-.23^{* *}$ & $.30^{* *}$ & $.39 * *$ & $.50^{* *}$ & $.43^{* *}$ & $.48^{* *}$ & $.43^{* *}$ & & \\
\hline 9. Age & 38.4 & 10.5 & -0.01 & 0.07 & -0.06 & $-.16^{* *}$ & $-.15^{* *}$ & $-.09^{*}$ & $-.15^{* *}$ & -0.07 & \\
\hline 10. Gender & 0.90 & 0.30 & 0.02 & $-.08^{*}$ & -0.01 & -0.03 & -0.02 & -0.04 & -0.02 & 0.00 & 0.06 \\
\hline
\end{tabular}

Note. ${ }^{*}$ indicates $p<.05 ;{ }^{* *}$ indicates $p<.01 . M$ and $S D$ are used to represent mean and standard deviation, respectively

nurses' wellbeing; however, the reduction in wellbeing was especially pronounced among nurses who felt like a victim. In addition, we have shown that each of the facets of the listening measure-constructive listening and destructive listening-had an incremental validity in predicting exposure to disruptive behaviors. Finally, we found, although we did not anticipate it, that the effect of exposure to disruptive behavior on wellbeing was curvilinear. Specifically, at a low range of exposure, there were no apparent effects on wellbeing, but at a high level of exposure, every increment in exposure translated into an accelerating damage to wellbeing, where this effect was especially pronounced among nurses who felt as a victim.

Our findings about the importance of listening in buffering exposure to disruptive behaviors joins other findings suggesting that listening is associated with low levels of violence $[11,17,23,30,32]$. It may hint that training staff in listening to each other may contribute to a reduction in disruptive behavior. One way to change quickly the listening behavior among nurses could involve "Listening Circles", also known as "The Council" [21]. Indeed, participating in "Listening Circles" at the workplace have been shown to reduce attitude extremity
[21], which may hint that not only such training can increase listening, but that it may also reduce disruptive behaviors.

Training nurses in listening, which is an important communication skill, can have benefits beyond reducing disruptive behaviors. Specifically, nurses who listen well may contribute to the wellbeing of their patients [41]. Indeed, deliberate listening by nurses seems to reduce depression among mothers to premature newborns; in addition, listening by the medical staff, including nurses, is associated with satisfaction with hospitalization [22], and reducing worries of mothers to newborns [49].

Second, our findings replicate previous ones showing that exposure to disruptive behavior is associated with reduced wellbeing. These results point out the irony that the medical staff who are supposed to heal the sick, nevertheless often behave in a way that has a negative effect on other nurses and consequently on patients. Third, our work suggests that exposure to disruptive behavior does not necessarily lead to a reduction in wellbeing. Specifically, it appears that only some people, who are exposed to high levels of disruptive behaviors, are at risk of reduced wellbeing. Nurses who feel as a victim are especially prone to the damage of exposure to

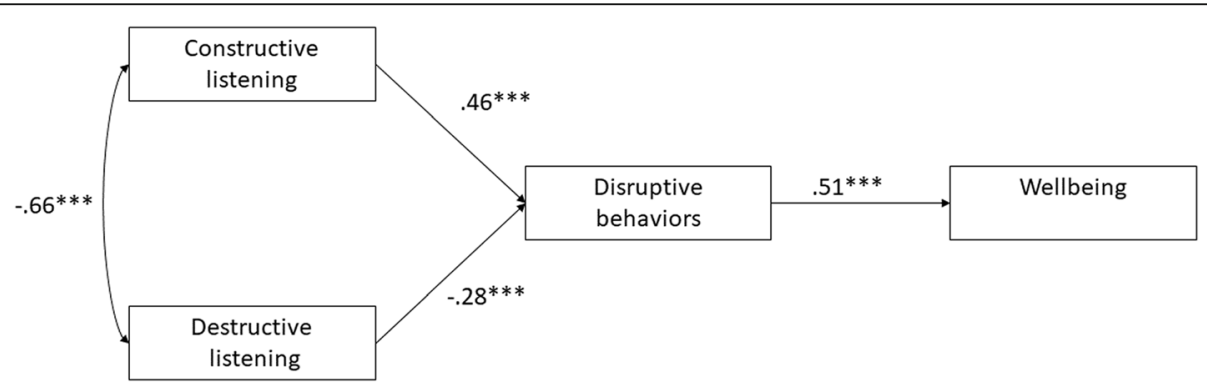

Fig. 2 A path analysis demonstrating (a) incremental validity of two listening scales in predicting disruptive behaviors and (b) the role of disruptive behaviors as a mediator of the effects of listening on wellbeing 
Table 3 Predicting wellbeing from exposure to disruptive behavior, feeling as a victim, non-linear effects of the above, and an interaction between them

\begin{tabular}{llll}
\hline Predictor & $\beta$ & $t$ & $P$ \\
\hline Disruptive & .45 & 9.67 & $<.0001$ \\
Disruptive $^{2}$ & -.15 & -3.85 & $<.0002$ \\
Feeling as victim $^{2}$ & .34 & 7.23 & $<.0001$ \\
Feeling as victim $^{2}$ & .00 & 0.13 & $=.90$ \\
Disruptive * Feeling as victim $^{\text {. }}$ & .13 & 3.66 & $<.0002$ \\
\hline
\end{tabular}

disruptive behaviors. Thus, it might be desirable to identify nurses that are at risk and to consider interventions geared toward reducing the feeling as a victim. Such as support groups, facilitating personal sessions with a social worker or psychologist from the organization, etc.

\section{Generalization}

We recruited nurses into our study through social media and snowball sampling. This method has the advantage of sampling nurses across multiple medical establishments and specialties. This sampling increases our ability to generalize our findings to many types of nurses. However, our sample might be biased such that certain types of nurses chose to participate (like those who spend more time surfing the internet). In addition, our study was done in Israel. Yet, the components of our model were tested and validated in other cultures (e.g., the link between listening and low level of violence among non-nurses, the link between exposure to

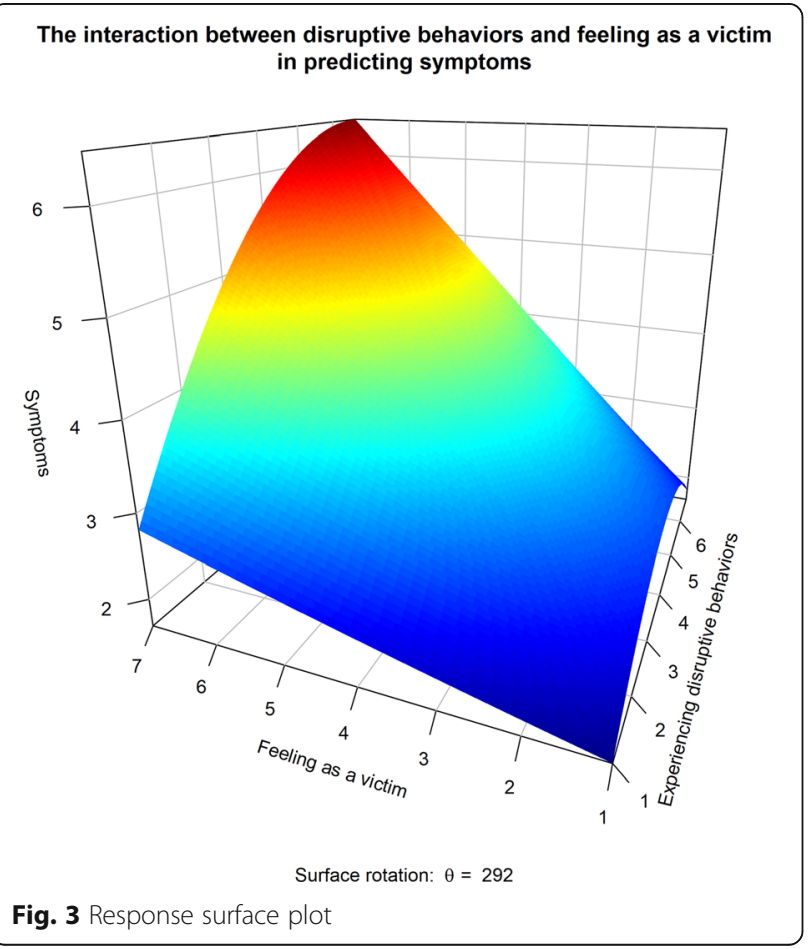

disruptive behaviors and wellbeing); thus, our results are likely to be generalizable to other cultures.

\section{Limitations}

The most obvious limitation of our study was its crosssectional design. Future research could attempt to replicate our findings with an experimental design. For example, wards could be randomized into participating, or placed on a waiting list, for listening training, and levels of disruptive behaviors before and after the training could be measured. Similarly, nurses who feel like a victim could be randomized into training design to reduce these feelings and changes in the wellbeing of those nurses could be tracked, especially among those who work in a ward characterized by high levels of disruptive behaviors. We believe that our results that are based on a relatively large sample justify the extra effort needed to re-test our model with experimental design in the field.

\section{Conclusions}

Past research indicates that exposure to disruptive behaviors among nurses is negatively associated with their wellbeing. We replicated these results and offered a model extending these findings to explain both one antecedent of disruptive behavior (listening) and one moderator (feeling as a victim). Specifically, we have shown that nurses who perceive their colleagues to be highly adept at listening also report low levels of exposure to disruptive behaviors. This may suggest that training nurses in listening skills could contribute to their wellbeing by reducing the incidents of disruptive behaviors. In addition, we have shown that the negative effects on wellbeing emanating from exposure to disruptive behavior are especially acute among nurses who felt as a victim. "Interventions targeted to this specific group could help them cope better with disruptive behavior."

In sum, our findings suggest that good quality listening skills among medical staff members will improve the quality of the work life of the nurses, and consequently contribute to the wellbeing of all people interacting with them.

\section{Acknowledgements \\ Not applicable.}

\section{Authors' contributions}

SS-T, ANK, YL designed the research together. SS-T and YL distributed the questionnaire. SS-T and ANK analyzed, interpreted the data and wrote the article with YL comments and review. We declare that all authors met the criteria for authorship, approved the final article and all those entitled to authorship are listed as authors.

\section{Funding}

This research was supported by grants from the Recanati Fund at the School of Business Administration, and The Israel Science Foundation (Grant 928/17) to the second author. 


\section{Availability of data and materials}

The datasets used and/or analysed during the current study available from the corresponding author on reasonable request.

\section{Ethics approval and consent to participate}

Prior to the distribution of this survey, we obtained an approval from the Institutional Review Board of the Jerusalem College of Technology. Anonymity was promised and all data were coded without identifying details and were used for research purposes only. Filling out the questionnaires was considered consent to participate in the study.

\section{Consent for publication}

Not applicable.

\section{Competing interests}

The authors declare that they have no competing interests.

\section{Author details}

${ }^{1}$ Hadassah University medical Hospital, Jerusalem, Israel. ${ }^{2}$ Jerusalem College of Technology, Jerusalem, Israel. ${ }^{3}$ School of Business Administration, The Hebrew University of Jerusalem, 91905 Jerusalem, Israel.

Received: 6 December 2018 Accepted: 9 September 2019

Published online: 04 November 2019

\section{References}

1. Allen BC, Holland P, Reynolds R. The effect of bullying on burnout in nurses: the moderating role of psychological detachment. J Adv Nurs. 2015;71(2): 381-90. https://doi.org/10.1111/jan.12489.

2. Bardakci E, Gunusen NP. Influence of workplace bullying on Turkish Nurses' psychological distress and Nurses' reactions to bullying. J Transcult Nurs. 2016;27(2):166-71. https://doi.org/10.1177/1043659614549073.

3. Berry PA, Gillespie GL, Gates D, Schafer J. Novice nurse productivity following workplace bullying. J Nurs Scholarsh. 2012;44(1):80-7. https://doi. org/10.1111/j.1547-5069.2011.01436.x.

4. Beune K, Giebels E, Sanders K. Are you talking to me? Influencing behaviour and culture in police interviews. Psychol Crime Law. 2009;15(7):597-617. https://doi.org/10.1080/10683160802442835

5. Blair PL. Lateral violence in nursing. J Emerg Nurs. 2013;39(5):e75-8.

6. Canlas JM, Miller RB, Busby DM, Carroll JS. Same-race and interracial AsianWhite couples: relational and social contexts and relationship outcomes. J Comp Fam Stud. 2015;46(3):307-28. https://doi.org/10.3138/jcfs.46.3.307.

7. Castro DR, Kluger AN, Itzchakov G. Does avoidance-attachment style attenuate the benefits of being listened to? Eur J Soc Psychol. 2016;46(6): 762-75. https://doi.org/10.1002/ejsp.2185.

8. Castronovo MA, Pullizzi A, Evans S. Nurse Bullying: A Review And A Proposed Solution. Nurs Outlook. 2016;64(3):208-14. https://doi.org/10.1016/ j.outlook.2015.11.008.

9. Clarke CM, Kane DJ, Rajacich DL, Lafreniere KD. Bullying in undergraduate clinical nursing education. J Nurs Educ. 2012;51(5):269-76. https://doi.org/10. 3928/01484834-20120409-01.

10. Dodge R, Daly AP, Huyton J, Sanders LD. The challenge of defining wellbeing. Int J Wellbeing. 2012;2(3):222-38.

11. Dong $X Q$, Simon $M A$. Is greater social support a protective factor against elder mistreatment? Gerontology. 2008;54(6):381-8. https://doi. org/10.1159/000143228

12. Drollinger T, Comer LB. Salesperson's listening ability as an antecedent to relationship selling. J Bus Ind Mark. 2013;28(1):50-9. https://doi.org/10.1108/ 08858621311285714

13. Embree $\mathrm{L}$, White $\mathrm{AH}$. Concept analysis: nurse-to-nurse lateral violence. Nurs Forum. 2010;45(3):166-73. https://doi.org/10.1111/j.1744-6198.2010.00185.x.

14. Falcione RL, McCroskey JC, Daly JA. Job satisfaction as a function of Employees' communication apprehension, self-esteem, and perceptions of their immediate supervisors. Ann Int Commun Assoc. 1977;1(1):363-75. https://doi.org/10.1080/23808985.1977.11923692.

15. Ganz, Freda DeKeyser, Levy, Hadassa, Khalaila, Rabia, Arad, Dana, Bennaroch, Kochav, Kolpak, Orly, ... Raanan, Ofra. (2015). Bullying and its prevention among intensive care nurses. J Nurs Scholarsh, 47(6), 505-511. doi:https:// doi.org/10.1111/jnu.12167.

16. Ganzach Y. Misleading interaction and curvilinear terms. Psychol Methods. 1997;2(3):235-47.
17. Holtzworth-Munroe A, Stuart GL, Sandin E, Smutzler N, McLaughlin W Comparing the social support behaviors of violent and nonviolent husbands during discussions of wife personal problems. Pers Relat. 1997; 4(4):395-412. https://doi.org/10.1111/j.1475-6811.1997.tb00153.x.

18. http://bit.ly/2vdzkCP. (2008). Behaviors that undermine a culture of safety - joint commission.

19. Hutchinson M, Wilkes L, Jackson D, Vickers MH. Integrating individual, work group and organizational factors: testing a multidimensional model of bullying in the nursing workplace. J Nurs Manag. 2010;18(2):173-81. https:// doi.org/10.1111/j.1365-2834.2009.01035.x.

20. Itzchakov G, Kluger AN. The listening circle: a simple tool to enhance listening and reduce extremism among employees. Organ Dyn. 2017;46(4):220-6.

21. Itzchakov G, Kluger AN, Castro DR. I am aware of my inconsistencies but can tolerate them:the effect of high quality listening on speakers' attitude ambivalence. Personal Soc Psychol Bull. 2017;43(1):105-20. https://doi.org/ 10.1177/0146167216675339.

22. Kahn SA, lannuzzi JC, Stassen NA, Bankey PE, Gestring M. Measuring satisfaction: factors that drive hospital consumer assessment of healthcare providers and systems survey responses in a trauma and acute care surgery population. Am Surg. 2015;81(5):537-43.

23. Katz LF, Woodin EM. Hostility, hostile detachment, and conflict engagement in marriages: effects on child and family functioning. Child Dev. 2002;73(2): 636-51. https://doi.org/10.1111/1467-8624.00428.

24. Kline RB. Principles and practice of structural equation modeling. 3rd ed. New York: Guilford Press; 2011.

25. Kluger AN, Bouskila-Yam O. Facilitating listening scale. In: Worthington DL, Bodie GD, editors. The sourcebook of listening research: Methodology and measures. Hoboken: Wiley; 2018. p. 272-80.

26. Kluger AN, Zaidel K. Are listeners perceived as leaders? Int J Listening. 2013; 27(2):73-84. https://doi.org/10.1080/10904018.2013.754283.

27. Laschinger HK. Impact of workplace mistreatment on patient safety risk and nurse-assessed patient outcomes. J Nurs Adm. 2014;44(5):284-90. https:// doi.org/10.1097/NNA.0000000000000068.

28. Lipetz L, Kluger AN, Bodie GD. Listening is listening is listening: employees' perception of listening as a holistic phenomenon. Int J Listening. 2018:1-26. https://doi.org/10.1080/10904018.2018.1497489.

29. Lopez-Rosenfeld M, Calero Cl, Fernandez Slezak D, Garbulsky G, Bergman M, Trevisan M, Sigman M. Neglect in human communication: quantifying the cost of cell-phone interruptions in face to face dialogs. PLoS One. 2015;10(6):e0125772. https://doi.org/ 10.1371/journal.pone.0125772.

30. Marcus RF, Swett B. Violence and intimacy in close relationships. J Interpers Violence. 2002;17(5):570-86. https://doi.org/10.1177/0886260502017005006.

31. Martin WF. Is your hospital safe? Disruptive behavior and workplace bullying. Hosp Top. 2008;86(3):21-8. https://doi.org/10.3200/HTPS.86.3.21-28.

32. Merritt DH, Snyder SM. Maltreatment type and behaviors: does listening matter? Child Abuse Negl. 2014;38(12):2062-71. https://doi.org/10.1016/j. chiabu.2014.10.019.

33. Olsen E, Bjaalid G, Mikkelsen A. Work climate and the mediating role of workplace bullying related to job performance, job satisfaction, and work ability: a study among hospital nurses. J Adv Nurs. 2017;00:1), 1-11. https:// doi.org/10.1111/jan.13337.

34. Purpora C, Blegen MA, Stotts NA. Hospital staff registered nurses' perception of horizontal violence, peer relationships, and the quality and safety of patient care. Work. 2015;51(1):29-37. https://doi.org/10. 3233/WOR-141892.

35. Purpora C, USA, University of San Francisco (USF) School of Nursing and Health Professions San Francisco CA, Blegen, Mary A, University of California, San Francisco (UCSF) San Francisco CA USA, \& USA, University of Colorado Denver CO. Job satisfaction and horizontal violence in hospital staff registered nurses: the mediating role of peer relationships. J Clin Nurs. 2015; 24(15-16):2286-94. https://doi.org/10.1111/jocn.12818.

36. Reknes I, Pallesen S, Magerøy N, Moen BE, Bjorvatn B, Einarsen S. Exposure to bullying behaviors as a predictor of mental health problems among Norwegian nurses: results from the prospective SUSSH-survey. Int J Nurs Stud. 2014;51(3):479-87. https://doi.org/10.1016/j.jijnurstu.2013.06.017.

37. Rocker CF. Addressing nurse-to-nurse bullying to promote nurse retention. Online J Issues Nurs. 2008;13:3.

38. Rogers CR, Roethlisberger FJ. Barriers and gateways to communication. Harv Bus Rev. 1991;69(6):105-11. 
39. Rosenstein AH, O'Daniel M. Invited article: managing disruptive physician behavior: impact on staff relationships and patient care. Neurology. 2008; 70(17):1564-70. https://doi.org/10.1212/01.wnl.0000310641.26223.82.

40. Schnittker J. Social distance in the clinical encounter: interactional and sociodemographic foundations for mistrust in physicians. Soc Psychol Q. 2004;67(3):217-35. https://doi.org/10.1177/019027250406700301.

41. Segre LS, Brock RL, O'Hara MW. Depression treatment for impoverished mothers by point-of-care providers: a randomized controlled trial. J Consult Clin Psychol. 2015;83(2):314-24. https://doi.org/10.1037/a0038495.

42. Spence Laschinger HK, Nosko A. Exposure to workplace bullying and posttraumatic stress disorder symptomology: the role of protective psychological resources. J Nurs Manag. 2015;23(2):252-62. https://doi.org/10. 1111/jonm.12122.

43. Stagg SJ, Sheridan D. Effectiveness of bullying and violence prevention programs. AAOHN J. 2010:58(10):419-24. https://doi.org/10.1177/ 216507991005801003.

44. Stanley KM, Martin MM, Michel Y, Welton JM, Nemeth LS. Examining lateral violence in the nursing workplace. Issues Ment Health Nurs. 2009;28(11): 1247-65. https://doi.org/10.1080/01612840701651470.

45. Tangirala S, Ramanujam R. Ask and you shall hear (but not always): examining the relationship between manager consultation and employee voice. Pers Psychol. 2012;65(2):251-82. https://doi.org/10.1111/ j.1744-6570.2012.01248.x

46. Trépanier S-G, Fernet C, Austin S, Boudrias V. Work environment antecedents of bullying: a review and integrative model applied to registered nurses. Int J Nurs Stud. 2016;55:85-97.

47. Ulrich DL, Gillespie GL, Boesch MC, Bateman KM, Grubb PL. Reflective responses following a role-play simulation of nurse bullying. Nurs Educ Perspect. 2017;38(4):203-5. https://doi.org/10.1097/01.nep. 0000000000000144

48. Weaver KB. The effects of horizontal violence and bullying on new nurse retention. J Nurses Prof Dev. 2013;29(3):138-42.

49. Wiggins, M, Oakley, A, Roberts, I, Turner, H, Rajan, L, Austerberry, H, . . . Barker, M. (2005). Postnatal support for mothers living in disadvantaged inner city areas: a randomised controlled trial. J Epidemiol Community Health, 59(4), 288-295. doi:https://doi.org/10.1136/jech.2004.021808.

\section{Publisher's Note}

Springer Nature remains neutral with regard to jurisdictional claims in published maps and institutional affiliations.

Ready to submit your research? Choose BMC and benefit from:

- fast, convenient online submission

- thorough peer review by experienced researchers in your field

- rapid publication on acceptance

- support for research data, including large and complex data types

- gold Open Access which fosters wider collaboration and increased citations

- maximum visibility for your research: over $100 \mathrm{M}$ website views per year

At $\mathrm{BMC}$, research is always in progress.

Learn more biomedcentral.com/submissions 